\title{
Leveraging Neural Networks in Preclinical Alcohol Research
}

\author{
Lauren C. Smith ${ }^{1}$ (D) and Adam Kimbrough ${ }^{1,2, *(\mathbb{D})}$ \\ 1 Department of Psychiatry, School of Medicine, University of California San Diego, MC 0667, La Jolla, \\ CA 92093, USA; las005@ucsd.edu \\ 2 Department of Basic Medical Sciences, College of Veterinary Medicine, Purdue University, \\ 625 Harrison Street, West Lafayette, IN 47907, USA \\ * Correspondence: kimbroua@purdue.edu; Tel.: +1-765-494-8637
}

Received: 12 July 2020; Accepted: 18 August 2020; Published: 21 August 2020

check for updates

\begin{abstract}
Alcohol use disorder is a pervasive healthcare issue with significant socioeconomic consequences. There is a plethora of neural imaging techniques available at the clinical and preclinical level, including magnetic resonance imaging and three-dimensional (3D) tissue imaging techniques. Network-based approaches can be applied to imaging data to create neural networks that model the functional and structural connectivity of the brain. These networks can be used to changes to brain-wide neural signaling caused by brain states associated with alcohol use. Neural networks can be further used to identify key brain regions or neural "hubs" involved in alcohol drinking. Here, we briefly review the current imaging and neurocircuit manipulation methods. Then, we discuss clinical and preclinical studies using network-based approaches related to substance use disorders and alcohol drinking. Finally, we discuss how preclinical 3D imaging in combination with network approaches can be applied alone and in combination with other approaches to better understand alcohol drinking.
\end{abstract}

Keywords: addiction; dependence; substance use disorder; iDISCO; fMRI; modularity; graph theory; animal model; binge drinking; alcohol use disorder

\section{Introduction}

Alcohol abuse is a pervasive societal problem with substantial socioeconomic and medical consequences [1]. Alcohol use disorder (AUD) is a chronic relapsing disorder that is associated with the loss of control of ethanol drinking and compulsive drinking that is driven by the emergence of a negative affective state upon cessation [2,3]. The transition from casual drinking to alcohol dependence is thought to occur over time as the motivation to drink shifts from positive reinforcement to avoiding negative reinforcement [4]. Once dependent, three repeating stages are postulated to occur. The first stage being a period of excessive drinking, followed by a second stage involving a period of abstinence, resulting in negative affect symptoms, which then leads to the third stage that involves increased motivation and craving to drink $[3,5,6]$.

In humans, the emotional and physical signs of withdrawal from alcohol can manifest in several ways such as increased anxiety, increased irritability, increased frustration, increased aggression, mood swings, insomnia, tremors, convulsions, higher blood pressure, accelerated pulse, accelerated breathing, dehydration, and delirium tremens [7-14]. The emotional symptoms of withdrawal from alcohol dependence, including anxiety-like behavior, depression-like behavior, irritability-like behavior, and aggressive behavior can be modeled in rats and mice and can last for days to weeks after cessation of drinking [15-39]. 
Preclinical animal models, especially in rats and mice, are ideal for studying alcohol drinking and alcohol addiction due to the ability to adequately model negative affect and excessive drinking behavior. Some of the most prominent animal models to study excessive and binge-like drinking are the intermittent access to ethanol (IAE) model, using two-bottle choice [40-60], and the drinking in the dark (DID) model, using a single bottle [61-72]. For a comprehensive review of the behavioral methods used to study AUD in rodents, see Vendruscolo and Roberts and Tunstall et al. [73,74].

Rats and mice have also been selectively bred to express excessive drinking behavior, allowing for greater focus on genetic aspects associated with increased drinking. In rats, the alcohol-preferring strain, the high alcohol-drinking strain, and the Marchigian Sardinian alcohol-preferring rats have been examined [75-79], and in mice, high drinking in the dark mice and high alcohol-preferring mice have been examined [80-85].

To study excessive and compulsive-like drinking due to alcohol dependence, the intermittent ethanol (CIE) vapor exposure model has been heavily used in both rats and mice [16,55,86-105].

Although our knowledge of the neurocircuitry that underlies excessive alcohol drinking and alcohol dependence has improved dramatically over the last decade $[5,106]$, there is still a large need to further our understanding. Adequately advancing our understanding of the neurocircuitry involved in alcohol drinking will require research to continue to take advantage of quality preclinical models and emerging technological advancements in the field of neuroscience.

\section{Recently Developed Approaches in Preclinical Neuroscience}

The development of site-specific recombinase systems [107-109] has allowed for controlled mutations in preclinical models of disease [110]. Advances in cell-specific molecular genetics has built the foundation for the modern optogenetic, chemogenetic, and electrophysiology methods, used in cell-specific populations.

\subsection{Optogenetics}

The optogenetic method takes advantage of the genetic incorporation of light-gated cation channel channelrhdopsin-2 (ChR2) and chloride and proton pumps (i.e., halorhodpson and archaerhopsin) into neural tissue [111-113]. Neuron specific Cre recombinase expression allows for the use of viral vectors encoding Cre-inducible opsin proteins in specific brain regions [114]. Optogenetics can be used to map neural connections between specific sets of brain regions. Optogenetic manipulation can further reveal distinct circuits involved in behavioral and emotional states such as reward, stress, and anxiety-like behaviors [115].

Optogenetic approaches in preclinical models have been used to identify numerous circuits throughout the brain involved in alcohol drinking. Several studies have used optogenetic manipulation to identify projections from the central amygdala (CEA) that are critical for addiction-like behaviors [116-118]. Optogenetic manipulation of ventral tegmental area (VTA) neurons projecting to the nucleus accumbens (NAc) has identified a role for the VTA-NAc circuit in alcohol-drinking behavior [119-121]. Other circuits determined to be important for alcohol-related behaviors via optogenetics include an agranular insular cortex to basolateral amygdala (BLA) circuit [122] and a medial prefrontal cortex (mPFC) to NAc circuit. Interestingly, inhibition of the mPFC-NAc circuit was found to reduce alcohol drinking associated with quinine adulteration, suggesting the importance of the circuit for compulsive-like alcohol drinking [123]. While optogenetic approaches allow for precision in targeting neural circuits, they require surgical manipulation and active stimulation to produce inhibition or activation. Therefore, the approach examines the inhibition or activation of circuits for a period of seconds to minutes but not days to weeks, which may be needed to determine long-term effects. Optogenetics has been used to make great progress toward understanding the circuits mediating alcohol-related behavior and will likely continue to be an important approach in neuroscience. Chemogenetics are a complementary set of approaches that have similarly been used to explore circuits related to alcohol drinking. 


\subsection{Chemogenetics}

Designer receptors exclusively activated by a designer drug (DREADDs) are a class of chemogenetically engineered receptors activated by small molecules [124]. DREADDs are engineered G-protein coupled receptors that have been modified to be activated exclusively by synthetic compounds (e.g., clozapine-N-oxide). The use of DREADDs serves as a less invasive and more affordable alternative to optogenetic approaches. The expression of DREADDs in specific brain regions is usually achieved with stereotaxic injection of an Adeno-associated virus encoding Cre or flippase DNA recombinases. The development of transgenic DREADD reporter mice for Cre- or Flp-driven chemogenetic manipulation allows for brain-wide, cell-specific circuit investigation [124-126]. Several DREADD variants have been engineered using a G-protein coupled receptor or $\beta$-arrestin signaling components $[125,127,128]$. Similar to optogenetics, chemogenetics has been used to identify distinct neural circuits associated with behavioral and emotional states [127,129].

Several studies have taken advantage of chemogenetics to explore mechanisms of alcohol drinking. For example, a reduction of alcohol consumption in mice was found by a suppression of activity in the NAc core with hM4Di-mediated inhibition [130]. Pharmacological antagonism of the k-opioid receptor and chemogenetic silencing of dynorphin signaling neurons was used to identify a role for dynorphin/k-opioid receptor signaling in the central amygdala in excessive alcohol consumption in a rodent model of binge drinking [131]. Specific neuronal ensembles critical for alcohol dependent drinking within the CEA were identified by the chemogenetic silencing of activated neurons using Daun02 [91]. Inhibition of dorsal mPFC projections to the BLA via chemogenetics reduced withdrawal symptoms associated with abstinence for alcohol dependence [132]. With chemogenetic methods, receptors are targeted via the injection of a ligand, resulting in a less specific time of effect. Furthermore, some ligands may produce potential off-target effects depending on the dose used, thus requiring ligand-only controls [133-136]. Although optogenetics and chemogenetics tend to focus more on neural circuits, other techniques such as calcium imaging are necessary to determine the activity of individual neurons over time in a single brain region.

\subsection{Calcium Imaging}

Two-photon calcium imaging is a method for monitoring the in vivo activity of distinct neurons in brain tissue [137]. This allows for a real-time analysis of cells and subcellular compartments. Calcium imaging can also be used in in vitro studies in brain slices [138]. The combination of acetoxymethyl ester staining and calcium imaging techniques allows for the characterization of neural network activity on a larger scale [139]. Calcium imaging has been used to identify neural circuits involved in behaviors mediating substance use disorders (SUD) and AUD. For example, calcium imaging was able to identify neural activity patterns in $\mathrm{mPFC}$ neurons projecting to the periaqueductal gray that predicted the emergence of compulsive-like alcohol drinking behavior [140]. Calcium imaging is able to assess activity patterns of individual neurons; however, this approach is often limited to brain regions closer to the surface of the skull and does not examine the neural activity of the brain as a whole. Calcium imaging can also be performed using fiber photometry, which allows for access to deeper brain regions.

\subsection{Magnetic Resonance Imaging}

One of the most commonly used neuroimaging techniques is magnetic resonance imaging (MRI), which is relatively fast, non-invasive, and can be done in vivo. MRI takes advantage of the ability of atomic nuclei to absorb radio frequency (RF) in the presence of an external magnetic field [141]. Then, the nuclei emit an RF signal with intrinsic spin polarization that can be detected in a radio frequency coil. This method has evolved over time, and advanced applications are currently available to look at functional brain activity in human subjects and preclinical animal models [142,143]. Functional magnetic resonance imaging (fMRI) is a method that measures time-based changes in brain metabolism, which are functionally measured as changes in oxygenated blood during a neural response [143]. 
While MRI techniques are not a recent development, their application in determining structural and functional connectivity is a relatively new advancement in the field of neuroscience. Magnetic resonance imaging methods are useful to measure within-subjects; however, they require a head-fixed and anaesthetized state. Furthermore, imaging is only possible at a mesoscale resolution. Neural activity can be examined in preclinical animal models by using fMRI; however, there are limitations on the resolution of the activity patterns that may limit the usefulness in rodent models of disease.

\subsection{Three-Dimensional Imaging}

Recent developments in tissue-clearing methods allow for three-dimensional (3D) imaging of intact tissues, such as the whole brain. Hydrophobic and hydrophilic tissue-clearing methods are both solvent-based and generally remove lipids, pigments, and calcium phosphate to reach an appropriate refractive index for imaging. The 3D imaging of tetrahydrofuran (THF) cleared organs (3DISCO) was developed by Ertürk et al. The use of THF, a dehydrating and de-lipidating agent, instead of alcohol enhances the refractive index homogeneity of the samples [144]. Renier et al., developed the immunolabeling-enabled DISCO (iDISCO) method, which allows for whole-mount immunolabeling of whole cleared organs [145]. This technique was adapted and improved by removing the use of THF and instead only using methanol to dehydrate the tissue with iDISCO+ [146]. The 'ultimate' DISCO (uDISCO) technique, developed by Pan et al., was optimized for the preservation of endogenous fluorescence for months [147]. Hydrogel-based tissue clearing uses covalent linkage to an acryl-based hydrogel for complete lipid removal with limited structural damage and protein loss [148]. This method has been termed 'cleared lipid-extracted acryl-hybridized rigid immunostaining/in situ hybridization-compatible tissue hydrogel', or CLARITY. A summary of 3D imaging techniques and some of the pros and cons of each method are presented in Table 1. The availability of many 3D imaging methods allows researchers to tailor the method for a given experiment, each with their own advantage or disadvantage. With all 3D imaging methods, only between-subject timepoints are possible, as the method requires post-mortem data collection. Neural activity measured by 3D imaging can be immense and hard to interpret without combining the technique with network neuroscience to identify brain-wide neural activity at the network level.

Table 1. Three-dimensional (3D) imaging techniques. 3DISCO: 3D imaging of tetrahydrofuran (THF) cleared organs, iDISCO: immunolabeling-enabled DISCO, uDISCO: 'ultimate' DISCO, CLARITY: cleared lipid-extracted acryl-hybridized rigid immunostaining/in situ hybridization-compatible tissue hydrogel.

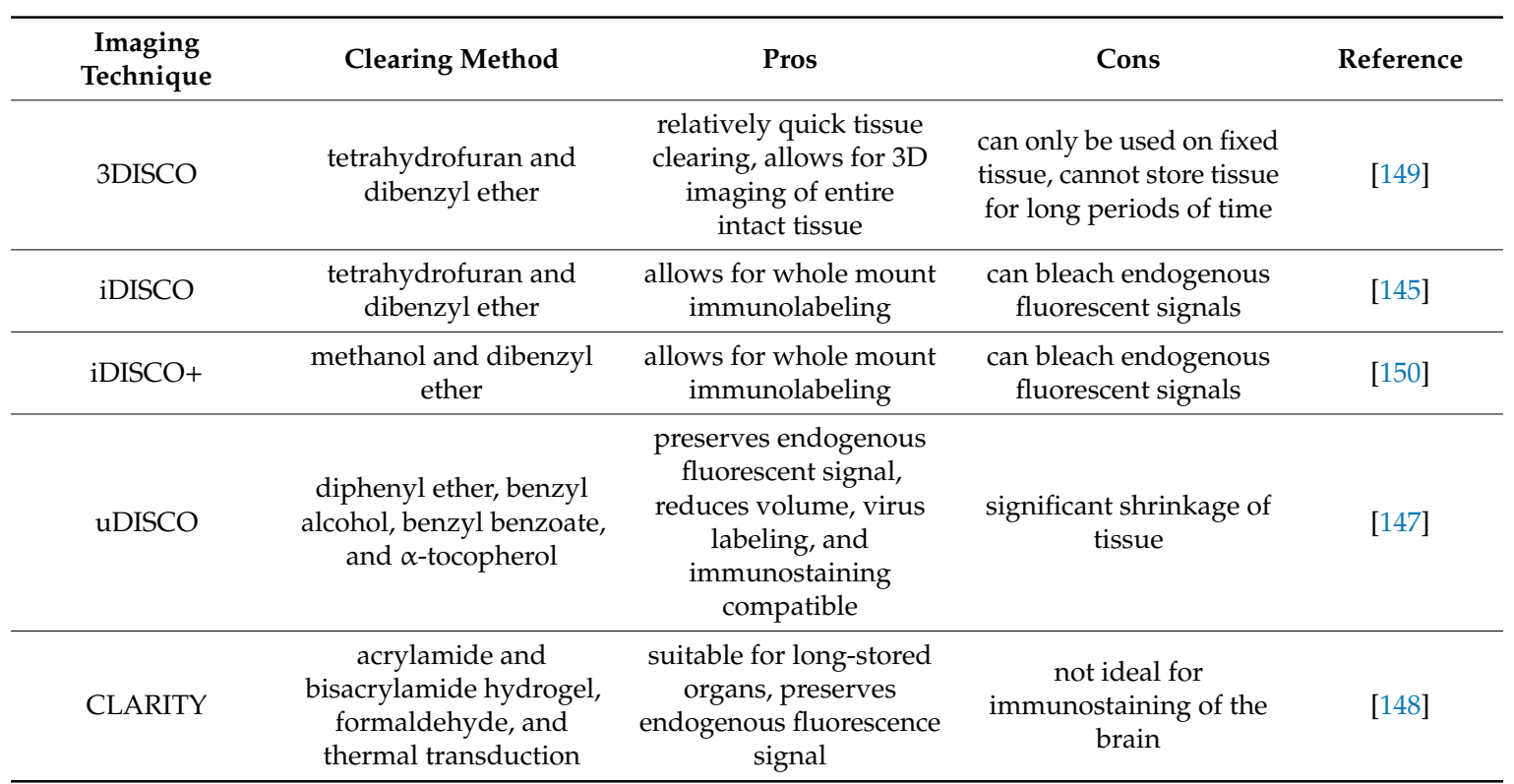




\section{Neural Networks}

Network-based approaches are highly applicable to neuroscience and have been used to analyze large sets of data. In neuroscience, networks can be examined at the structural or functional connectivity level. Structural networks are mapped by measuring the physical inter-neuronal connectivity or inter-regional connectivity, whereas functional networks examine the effective connectivity of neural activity between regions [151]. Methods for looking at structural connectivity include MRI, diffusion tensor imaging, and electron microscopy [152-155]. Functional connectivity can be measured using fMRI, electroencephalography (EEG), magnetoencephalography (MEG), or 3D imaging [156-166]. A summary of the methods used to model the functional and structural connectivity of the human brain is presented in Table 2.

Table 2. Methods used for human brain mapping.

\begin{tabular}{ccc}
\hline Method & Domain & References \\
\hline functional magnetic resonance imaging & Functional & {$[156-161]$} \\
electroencephalography & Functional & {$[162,163]$} \\
magnetoencephalography & Functional & {$[165-167]$} \\
diffusion tensor imaging & Structural & {$[152]$} \\
diffusion spectrum imaging & Structural & {$[153]$} \\
magnetic resonance imaging & Structural & {$[154,155]$} \\
\hline
\end{tabular}

Graph theory has been used to identify specific features of neural networks in more detail. Graph theory is a branch of mathematics that is used to analyze complex networks [129,168-179]. Graph theory can be applied to data across multiple levels of time and neural organization (e.g., whole brain, regions, circuits, neurons). Graph theory models the pairwise relations between vertices, or nodes, through interconnecting edges, which can be directed or undirected [180]. When modeling the brain, the node can be neurons or an anatomical brain region, and the edges can be the functional connectivity between them, as measured by the correlation of neural activity.

In terms of brain mapping, numerous studies have examined the human brain (Table 2). Many of the graph models of human brain imaging data show small-worldness and modular organization $[164,181]$. In graph theory, the "world" of a network is said to be "small" if the mean geodesic distance between node pairs is small relative to the total number of nodes. The geodesic distance is calculated by determining the minimum number of edges required to travel between two nodes [182]. Mathematically, as the number of nodes tends to infinity Equation (1), the mean geodesic (g) will grow slower than logarithmically Equation (2).

$$
\begin{gathered}
N \rightarrow \infty \\
g=r(\log N)
\end{gathered}
$$

Modularity is defined as the division of a network into modules. A network expressing high modularity consists of nodes with high intramodule connectivity and sparse intermodule connectivity [181]. Mathematically, modularity is calculated by taking the fraction of edges that fall within modules minus the expected fraction of edges. These topographical measures translate across methods and correlate with phenotypes and disease states. For example, in patients with schizophrenia, network analysis of EEG and fMRI data shows changes in the magnitude of connectivity across brain regions relative to healthy controls $[183,184]$. Additionally, general intelligence has been shown to be associated with topological measures of network efficiency in neural network analysis of functional and structural brain mapping data [185-187]. Graph theory can further be used to determine network features such as network efficiency and node centrality. Network efficiency is characterized by the average of the shortest path lengths between any pair of nodes, with lower values indicating higher efficiency $[164,188]$. Node centrality quantifies the importance of a node inside a network and can 
consider degree, efficiency [158], closeness, or betweenness [189]. These nodes are considered a hub in the network [190,191].

In modeling neural networks, hub brain regions will emerge that are characteristic of the specific brain state being examined. A hub is defined as a node with high connectivity to other nodes in the same module (provincial hubs) or to other modules (connector hubs) [191,192]. Hub brain regions are critical to network function and represent the highest level of connectivity $[99,129,171,190,193]$. An example of hub identification and validation in brain-wide neural networks can be seen in a study by Vetere et al., in which in silico node deletion and in vivo chemogenetic silencing of the identified nodes confirmed the connection between a region's node degree and role in memory consolidation [129]. Furthermore, important hubs identified in neural networks have been shown to be conserved across species and scales [194]. Going forward, network neuroscience has the potential to provide novel insights regarding how the brain functions as a whole in brain states associated with SUDs.

\section{Neural Networks in Clinical Models of Substance Use Disorders}

There have been attempts to identify modules and neurocircuitry involved in SUDs from large-scale analysis of prior literature $[106,195]$. However, the majority of the SUD studies leveraging neural network analysis have involved imaging data. Differential levels of functional connectivity in alcohol, tobacco, and concurrent alcohol and tobacco users compared to a control population that did not use substances have been determined by resting-state fMRI analysis [196]. The results showed a general reduction in functional connectivity among substance users, with hyper-connectivity to the precuneus observed in smokers. Smokers examined during abstinence, and after satiation, using whole brain resting-state fMRI were found to have functional neural adaptations in the anterior cingulate cortex and precuneus during withdrawal-induced craving [197]. The precuneus is involved in a variety of functions, including memory [198] and has been proposed as a core component of the default mode network [199]. The use of fMRI, combined with memory and cognition tasks, after administration of the psychostimulant methylphenidate in healthy individuals was used to identify key brain regions involved in regulating cognition [200,201]. Analysis of resting-state fMRI data from cocaine-dependent individuals after treatment with methylphenidate was used to identify connectivity patterns in the mesocorticolimbic system [202]. Studies of brain connectivity during cocaine dependence using MRI techniques have shown that cocaine use is associated with altered brain connectivity that is associated with behavioral performance, treatment outcomes, and history of use [203]. Cocaine use has also been found to alter the identification of brain hubs in neural networks [204]. Abstinent heroin-dependent users experienced increased impulsivity and greater intrinsic amygdala functional connectivity at resting state compared to controls [205]. Abstinence from heroin dependence has also been shown to decrease the resting-state functional connectivity of the anterior cingulate cortex, which was associated with cue-induced cravings for heroin [206].

Alcohol-dependent individuals and binge drinkers have been shown to have major alterations to functional connectivity in several studies. Resting-state functional connectivity in executive control brain regions has been found to be reduced in subjects suffering from AUD [207,208]. Acute alcohol intake was found to result in greater changes to functional connectivity in heavy drinkers than normal drinkers [209]. Increased functional connectivity has been observed in patients with AUD during acute withdrawal in task-based cue-reactivity fMRI studies, identifying brain regions involved in craving [210,211]. This was accompanied by cue-based functional dysconnectivity and resting-state hyperactivity in specific cortical and subcortical regions as measured by EEG [210]. This study supports the hypothesis of a network of alcohol-related brain areas connected to craving, including the amygdala, parahippocampus, NAc, striatum, posterior cingulate cortex, and VTA. Similarly, young adult binge drinkers were found to have greater connectivity between striatal areas associated with reward, such as the NAc, and salience-associated areas, such as the anterior cingulate cortex, and reduced connectivity of the prefrontal cortex and hippocampus [212]. Alcohol has been shown to reduce connectivity between the globus pallidus externus (GPe) and other brain regions in patients with history of alcohol 
use. In the same study, impulsivity was correlated with greater GPe connectivity during intoxication, and the contribution of drinking and impulsivity to GPe connectivity were found to be distinct [213]. Taken together, these highlighted studies indicate that major changes occur in the brain after using substances of abuse such as alcohol. However, there are limitations to the amount of detail that can be inferred from human studies; thus, there is a need to broaden neural network approaches to animal models of SUD.

\section{Leveraging Neural Networks in Preclinical Animal Models}

Network-based approaches can also be applied to preclinical animal models using imaging techniques such as fMRI, traditional immunohistochemistry, and whole-brain single-cell imaging (i.e., iDISCO). Figure 1 summarizes two of the available preclinical imaging techniques and their application to neural networks. Whole-brain single-cell imaging can capture a cognitive state (e.g., alcohol abstinence) at a single point in time, at a mesoscale resolution. Fos protein begins to be produced at detectable levels approximately $30 \mathrm{~min}$ after neural activity, and peaks at 60 to $90 \mathrm{~min}$, and returns to baseline at approximately $180 \mathrm{~min}$; thus, the data from Fos protein represents neural activity across minutes to hours. This method allows immunostaining for multiple proteins and combination with other approaches such as optogenetics, chemogenetics, or pharmacology. This approach allows for data to represent normal awake-behaving neural activity, allowing for multiple experimental paradigms to be explored. Some limitations to single-cell whole-brain imaging are that it is ex vivo and only samples a single timepoint. In contrast, fMRI can capture a time course within the same subjects in vivo with data representing neural activity across seconds per measurement. Some limitations to fMRI are lack of brain region specificity in the data and that the animals are either immobilized or anesthetized during sampling, which prevents assessing many experimental paradigms (Table 3).

A

A Technique

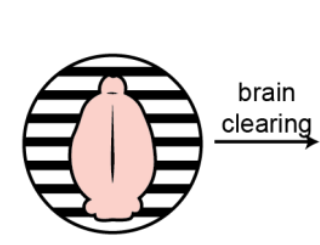

B

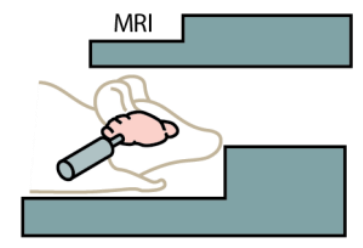

Scale and Time Resolution
Network Analysis

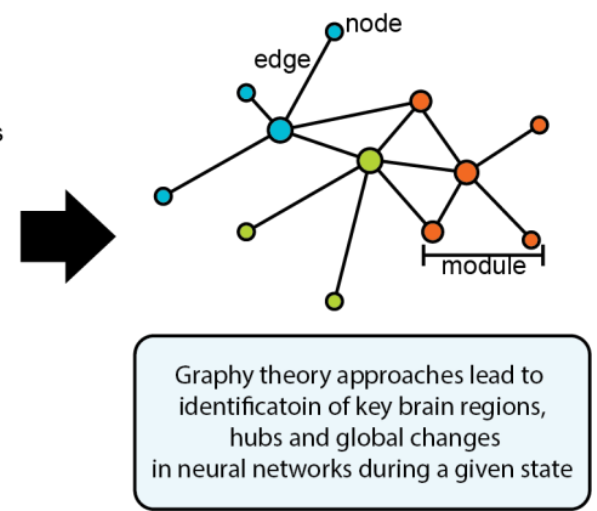

Figure 1. Illustration of imaging techniques used for neural network analysis of functional and structural brain connectivity. (A) Single-cell whole-brain imaging techniques, such as iDISCO, allow for analysis of the whole brain at the mesoscale (i.e., with region and cell-specific resolution), with results representing neural activity across minutes to hours. (B) Magnetic resonance imaging (MRI) techniques allow for analysis of the brain in more generalized resolution (i.e., at the macroscale) in anesthetized or immobilized animals, with results representing neural activity across seconds. Data from both of these methods can be interpreted using graph theory approaches to identify key brain regions, hubs, and global changes in neural networks during a given state. 
Table 3. Pros and cons of imaging techniques used for neural network analysis of functional and structural brain connectivity.

\begin{tabular}{cccc}
\hline Technique & Pros & Cons & References \\
\hline $\begin{array}{c}\text { Single-cell whole-brain } \\
\text { imaging }\end{array}$ & $\begin{array}{c}\text { mesoscale resolution (i.e., with } \\
\text { region and cell-specific), } \\
\text { organs taken in the freely } \\
\text { moving state }\end{array}$ & $\begin{array}{c}\text { single timepoint, post-mortem } \\
\text { measurements }\end{array}$ & {$[145,147,149,150]$} \\
MRI and fMRI & $\begin{array}{c}\text { repeatable measurement for } \\
\text { multiple timepoints } \\
\text { within-subject }\end{array}$ & $\begin{array}{c}\text { anesthetized or immobilized } \\
\text { during measurement, } \\
\text { generalized brain region } \\
\text { resolution (i.e., at the } \\
\text { macroscale) }\end{array}$ & {$[141-143,189]$} \\
\hline
\end{tabular}

\subsection{Preclinical Studies of Substance Use Disorders Using Functional Magnetic Resonance Imaging}

Functional MRI has been used in preclinical models of neurological disease and SUD to identify general trends in functional connectivity, as well as key brain regions and neural pathways involved in these states. Compared to controls, the thalamus was found to be heavily involved in the neural network activity of rats in acute abstinence from cocaine self-administration. Interestingly, changes in the neural network seen by fMRI measurement disappeared after 2 weeks [214]. A longitudinal study in a rodent model of alcohol use disorder utilized resting-state fMRI during a baseline measurement and after chronic alcohol use to determine a brain network and functional connectivity alterations associated with excessive alcohol drinking. An overall decrease in brain functional connectivity after chronic alcohol use and increased functional connectivity between the striatal and prefrontal-cingulate were found [215]. Although preclinical fMRI data can help to better understand brain function associated with SUD, the lack of resolution with regard to brain region specificity suggests that other approaches may be more beneficial in preclinical network neuroscience.

\subsection{Preclinical Studies of Substance Use Disorders Using Single-Cell Whole-Brain Imaging}

An unbiased approach to examine whole-brain neural activity by light-sheet fluorescent imaging of immunostained and optically cleared tissue has recently been developed (iDISCO) and used to uncover brain regions differentially activated during parenting behavior $[145,146]$. Another approach identified brain-wide maps of Fos mRNA expression during auditory fear conditioning to reveal patterns of Fos induction that are similar among shock-only and tone-only fear conditioning and fear recall conditions, suggesting simple associative learning ensembles that are activated by arousal rather than by a specific sensory cue [216].

Recent studies have begun to use protein detection of the immediate early gene Fos in combination with functional connectivity and network analysis. The quantification of 81 brain regions for Fos protein, using traditional immunohistochemistry, after fear conditioning led to the identification of a fear network [171]. This fear network was further examined using in vivo chemogenetic silencing of different network nodes to confirm the importance of the hubs predicted in network models [129]. Similarly, an unbiased brain-wide Fos protein approach, using the single-cell whole-brain imaging (iDISCO+) method, has been combined with functional connectivity and graph theory to identify changes to neural network structure and function caused by withdrawal from alcohol and psychostimulants [99,217].

Neural networks associated with withdrawal from individual psychostimulants (cocaine, methamphetamine, and nicotine) were identified in mice by using single-cell whole-brain imaging of neural activity [217]. While withdrawal from each drug produced a distinct pattern of brain activity, methamphetamine and cocaine had the most overlapping similarities. The common neuroadaptation between these psychostimulants was not necessarily changes in the connectivity of a specific group of brain regions, but an overall decrease in the modularity of the network. Global adaptations in the functional networks, such as decreased modularity, have been observed in other neuropsychiatric disorders, such as dementia, seizures, and traumatic brain injury [181,218-222]. 
Similarly, the unbiased single-cell whole-brain imaging and network analysis approach identified a massive increase in coactivation among brain regions and reduced modular structuring of the brain during abstinence from alcohol dependence when compared to control networks [99]. In the alcohol abstinence network, an overall structural simplification was observed, with three large modules identified that corresponded well to the classic three-stage theory of addiction $[3,5,6]$ : an extended amygdala module, a midbrain striatal module, and a cortico-hippocampo-thalamic module. This approach was able to verify the importance of regions within the extended amygdala that are known for their involvement in alcohol drinking and withdrawal, such as the CEA [23]. Additionally, brain regions of interest within the extended amygdala module, which may have been previously overlooked, were identified as targets for future research (Figure 2). These regions included the parasubthalamic nucleus, tuberal nucleus, cortical amygdala, and intercalated amygdala [99]. The findings related to alcohol abstinence [99] represent a small portion of the ways that whole-brain imaging and neural network-based approaches can be leveraged to ask and answer questions in the alcohol field going forward.

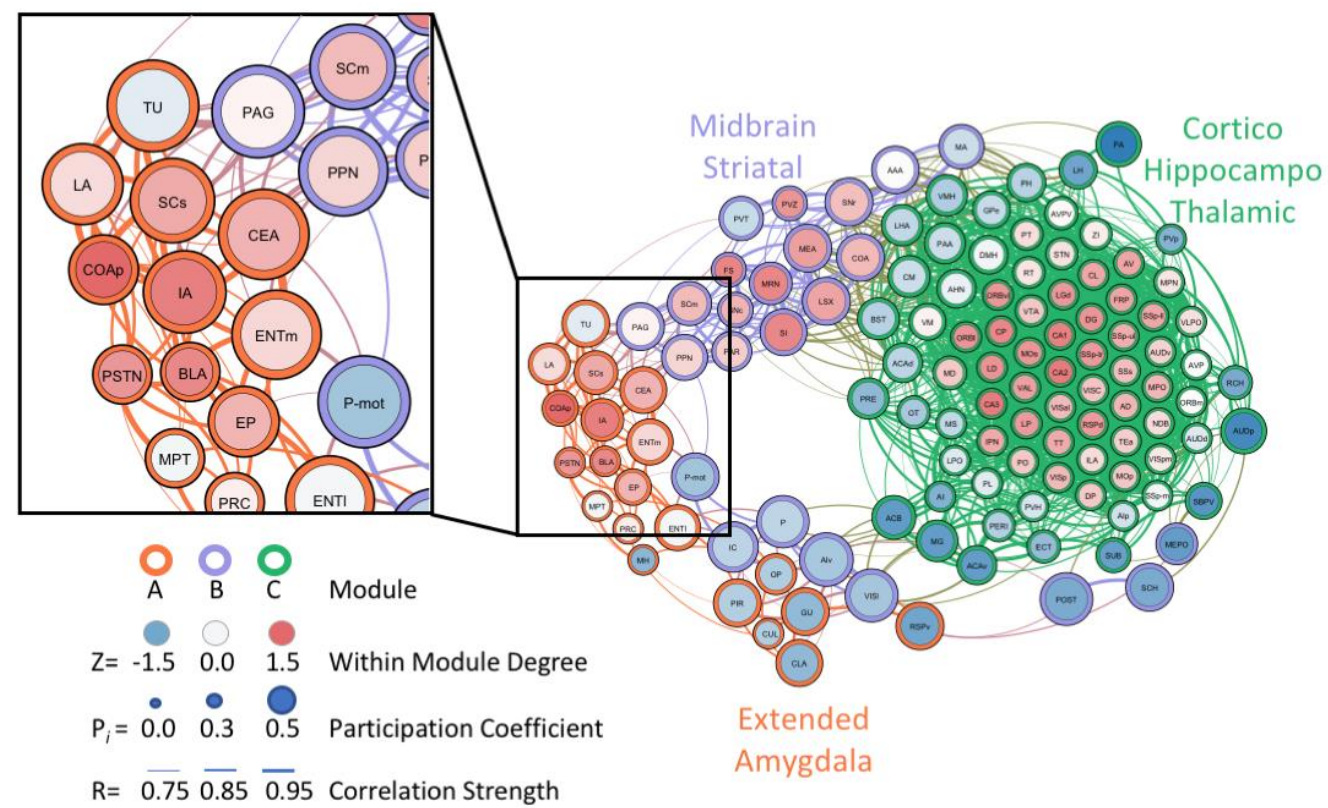

Figure 2. Graph theory representation of the neural network associated with alcohol abstinence in alcohol-dependent mice. Analysis identified several underexplored regions within the extended amygdala module that may be critical for withdrawal-associated behavior and excessive alcohol drinking. The zoomed-in panel highlights several of the underexplored regions, which include the posterior cortical amygdala (COAp), intercalated amygdala (IA), parasubthalamic nucleus (PSTN), and tuberal nucleus (TU). Figure reproduced and modified from Kimbrough et al., 2020 PNAS.

\subsection{Ways to Use Network-Based Approaches in the Preclinical Alcohol Field Going Forward}

The network-based approach using single-cell whole-brain imaging provides a unique opportunity to assess different aspects of alcohol drinking and AUD through various preclinical models (e.g., binge-like drinking, casual drinking etc.) and states of drinking/dependence depending on the question of interest. The different preclinical behavioral paradigms models (e.g., IAE, DID, CIE) of alcohol drinking and alcohol-preferring rodent strains can be used to assess neural networks across severities and conditions of alcohol drinking (e.g., binge drinking, alcohol dependent drinking, abstinence, etc.). Similarities and differences in brain-wide networks can be compared across alcohol drinking paradigms, and the unique components of a given network can be identified.

Perhaps most exciting of all is the possibility to combine single-cell whole-brain imaging and network analysis with other recently developed preclinical neuroscience technology. For example, 
the Targeted Recombination in Active Populations (TRAP) technique, in which mice contain a tamoxifen-dependent recombinase $\mathrm{CreER}^{\mathrm{T} 2}$ that is expressed in an activity-dependent manner from the loci of the immediate early genes Arc and Fos. This allows for the labeling of activated neurons at a given time/behavioral state (e.g., after a discrete drinking session, during intoxication, during withdrawal, etc.) while maintaining the ability for further testing before collection of the brain to examine neural networks $[223,224]$. Then, TRAP Fos labeling from a previous timepoint of neural activity (e.g., intoxication) can be combined with traditional Fos immunostaining to mark for natural immediate early gene protein production, using iDISCO, which is associated with neural activity from a time window shortly prior to euthanasia (e.g., protracted abstinence). Then, the neural activity from these two timepoints could be used together to assess neurons that are activated at both timepoints and potential similarities and differences in neural network activity between the two timepoints.

Preclinical network analysis using immediate early gene immunofluorescence can also be combined with immunostaining or endogenous fluorescence that signals specific neuronal cell types. This approach will provide information on a wide scale about what types of neurons and receptors contribute to overall network activity. Furthermore, viral tracing between brain regions can determine structural connections and then be used to compare structural to functional connectivity within a given network.

Optogenetics or DREADDs can be combined with single-cell whole-brain imaging to explore the effect of manipulation of specific circuits or cells on the neural connectivity of the whole brain. This approach would be ideal for delineating regions that play a role in a given behavior associated with the specific circuit but that is at the tertiary, quaternary, or further level of separation from the stimulation/inhibition. Additionally, using optogenetics or DREADDs to disrupt the activity of brain regions identified by network analysis combined with whole-brain imaging as "hub" regions associated with a behavioral state can verify their functional importance for the behavior. Calcium imaging can also be used to uncover more specific neuron-to-neuron local networks within a given brain region alongside an examination of brain-wide networks in the same animals. There is also the potential to use multi-brain region fiber photometry to collect neural activity data from neurons across a large number of brain regions [225], either independently, or as a complementary approach alongside single-cell whole brain imaging.

Traditional pharmacology with drug candidates that are potential medications to treat alcohol drinking can be explored as well using neural network approaches. It would be interesting to know how efficacious a given drug is at restoring the network function of the brain to a more normal state after a history of drinking. Perhaps current medications for the treatment of AUD, such as the FDA-pproved naltrexone, acamprostate, and disulfiram, only relieve changes to brain-wide network activity partially, or for a short period of time, which may explain to some degree the limited/moderate efficacy [226]. Interestingly, there is evidence that naltrexone alters functional connectivity in humans. Naltrexone was found to normalize local network efficiency in alcohol-dependent subjects [227]. Additionally, enhanced functional connectivity between the cingulate cortex and prefrontal cortex has been identified as a potential key component of the mechanism of action of naltrexone to treat alcohol drinking [228]. Overall, the preclinical field of alcohol addiction can benefit tremendously by taking advantage of single-cell whole-brain imaging and neural network approaches over the next several years.

\section{Conclusions}

Network-based approaches in preclinical studies have the potential to make significant contributions to our understanding of alcohol drinking. The combination with other relevant neuroscience approaches provides a unique opportunity to enhance our systems-based understanding of the brain in a way that was not previously available. Further, network analysis may help improve medication development and lead to better therapeutic options for AUD.

Author Contributions: L.C.S. and A.K. conceptualized, wrote, and edited the manuscript. All authors have read and agreed to the published version of the manuscript. 
Funding: This work was supported by National Institutes of Health grants DA047113 and AA027301. The content is solely the responsibility of the authors and does not necessarily represent the official views of the National Institutes of Health.

Conflicts of Interest: The authors declare no conflict of interest.

\section{References}

1. SAMHSA. Samhsa Alcohol Use Disorder in the Past Year, by Age Group and State: Percentages, Annual Averages Based on 2014 and 2015 NSDUHs. Available online: https://www.samhsa.gov (accessed on 12 July 2020).

2. Koob, G.F.; Ahmed, S.H.; Boutrel, B.; Chen, S.A.; Kenny, P.J.; Markou, A.; O'dell, L.E.; Parsons, L.H.; Sanna, P.P. Neurobiological mechanisms in the transition from drug use to drug dependence. Neurosci. Biobehav. Rev. 2004, 27, 739-749.

3. Koob, G.F.; Volkow, N.D. Neurocircuitry of addiction. Neuropsychopharmacology 2010, 35, 217-238.

4. Edwards, S.; Koob, G.F. Escalation of drug self-administration as a hallmark of persistent addiction liability. Behav. Pharmacol. 2013, 24, 356-362.

5. Koob, G.F.; Volkow, N.D. Neurobiology of addiction: A neurocircuitry analysis. Lancet Psychiatry 2016, 3, 760-773.

6. Koob, G.F.; Le Moal, M. Drug abuse: Hedonic homeostatic dysregulation. Science 1997, 278, 52-58.

7. Schuckit, M.A.; Tipp, J.E.; Reich, T.; Hesselbrock, V.M.; Bucholz, K.K. The histories of withdrawal convulsions and delirium tremens in 1648 alcohol dependent subjects. Addiction 1995, 90, 1335-1347.

8. Finn, D.A.; Crabbe, J.C. Exploring alcohol withdrawal syndrome. Alcohol Health Res. World 1997, 21, $149-156$.

9. Miczek, K.A.; Debold, J.F.; Hwa, L.S.; Newman, E.L.; De Almeida, R.M. Alcohol and violence: Neuropeptidergic modulation of monoamine systems. Ann. N. Y. Acad. Sci. 2015, 1349, 96-118.

10. Cardoso, J.M.; Barbosa, A.; Ismail, F.; Pombo, S. Neter alcoholic typology (NAT). Alcohol 2006, 41, $133-139$.

11. Winward, J.L.; Bekman, N.M.; Hanson, K.L.; Lejuez, C.W.; Brown, S.A. Changes in emotional reactivity and distress tolerance among heavy drinking adolescents during sustained abstinence. Alcohol. Clin. Exp. Res. 2014, 38, 1761-1769.

12. Baars, M.Y.; Muller, M.J.; Gallhofer, B.; Netter, P. Relapse (number of detoxifications) in abstinent male alcohol-dependent patients as related to personality traits and types of tolerance to frustration. Neuropsychobiology 2013, 67, 241-248.

13. Lubman, A.; Emrick, C.; Mosimann, W.F.; Freedman, R. Altered mood and norepinephrine metabolism following withdrawal from alcohol. Drug Alcohol Depend. 1983, 12, 3-13.

14. Miczek, K.A.; Fish, E.W.; De Almeida, R.M.; Faccidomo, S.; Debold, J.F. Role of alcohol consumption in escalation to violence. Ann. N. Y. Acad. Sci. 2004, 1036, 278-289.

15. Hwa, L.S.; Nathanson, A.J.; Shimamoto, A.; Tayeh, J.K.; Wilens, A.R.; Holly, E.N.; Newman, E.L.; Debold, J.F.; Miczek, K.A. Aggression and increased glutamate in the $\mathrm{mPFC}$ during withdrawal from intermittent alcohol in outbred mice. Psychopharmacology (Berlin) 2015, 232, 2889-2902.

16. Kimbrough, A.; De Guglielmo, G.; Kononoff, J.; Kallupi, M.; Zorrilla, E.P.; George, O. CRF1 receptor-dependent increases in irritability-like behavior during abstinence from chronic intermittent ethanol vapor Exposure. Alcohol. Clin. Exp. Res. 2017, 41, 1886-1895.

17. Pleil, K.E.; Lowery-Gionta, E.G.; Crowley, N.A.; Li, C.; Marcinkiewcz, C.A.; Rose, J.H.; Mccall, N.M.; Maldonado-Devincci, A.M.; Morrow, A.L.; Jones, S.R.; et al. Effects of chronic ethanol exposure on neuronal function in the prefrontal cortex and extended amygdala. Neuropharmacology 2015, 99, 735-749.

18. Marcinkiewcz, C.A.; Dorrier, C.E.; Lopez, A.J.; Kash, T.L. Ethanol induced adaptations in 5-HT2c receptor signaling in the bed nucleus of the stria terminalis: Implications for anxiety during ethanol withdrawal. Neuropharmacology 2015, 89, 157-167.

19. Thorsell, A.; Johnson, J.; Heilig, M. Effect of the adenosine A2a receptor antagonist 3,7-dimethyl-propargylxanthine on anxiety-like and depression-like behavior and alcohol consumption in Wistar Rats. Alcohol. Clin. Exp. Res. 2007, 31, 1302-1307.

20. Varlinskaya, E.I.; Kim, E.U.; Spear, L.P. Chronic intermittent ethanol exposure during adolescence: Effects on stress-induced social alterations and social drinking in adulthood. Brain Res. 2017, 1654, 145-156. 
21. Kallupi, M.; Vendruscolo, L.F.; Carmichael, C.Y.; George, O.; Koob, G.F.; Gilpin, N.W. Neuropeptide YY (2)R blockade in the central amygdala reduces anxiety-like behavior but not alcohol drinking in alcohol-dependent rats. Addict. Biol. 2014, 19, 755-757.

22. Gilpin, N.W.; Karanikas, C.A.; Richardson, H.N. Adolescent binge drinking leads to changes in alcohol drinking, anxiety, and amygdalar corticotropin releasing factor cells in adulthood in male rats. PLoS ONE 2012, 7, e31466.

23. Gilpin, N.W.; Herman, M.A.; Roberto, M. The central amygdala as an integrative hub for anxiety and alcohol use disorders. Biol. Psychiatry 2015, 77, 859-869.

24. Heilig, M.; Egli, M.; Crabbe, J.C.; Becker, H.C. Acute withdrawal, protracted abstinence and negative affect in alcoholism: Are they linked? Addict. Biol. 2010, 15, 169-184.

25. Kliethermes, C.L.; Cronise, K.; Crabbe, J.C. Anxiety-like behavior in mice in two apparatuses during withdrawal from chronic ethanol vapor inhalation. Alcohol. Clin. Exp. Res. 2004, 28, 1012-1019.

26. Pandey, S.C.; Sakharkar, A.J.; Tang, L.; Zhang, H. Potential role of adolescent alcohol exposure-induced amygdaloid histone modifications in anxiety and alcohol intake during adulthood. Neurobiol. Dis. 2015, 82, 607-619.

27. Pandey, S.C.; Roy, A.; Zhang, H. The decreased phosphorylation of cyclic adenosine monophosphate (cAMP) response element binding (CREB) protein in the central amygdala acts as a molecular substrate for anxiety related to ethanol withdrawal in rats. Alcohol. Clin. Exp. Res. 2003, 27, 396-409.

28. Valdez, G.R.; Sabino, V.; Koob, G.F. Increased anxiety-like behavior and ethanol self-administration in dependent rats: Reversal via corticotropin-releasing factor-2 receptor activation. Alcohol. Clin. Exp. Res. 2004, 28, 865-872.

29. Valdez, G.R.; Roberts, A.J.; Chan, K.; Davis, H.; Brennan, M.; Zorrilla, E.P.; Koob, G.F. Increased ethanol self-administration and anxiety-like behavior during acute ethanol withdrawal and protracted abstinence: Regulation by corticotropin-releasing factor. Alcohol. Clin. Exp. Res. 2002, 26, 1494-1501.

30. Ehlers, C.L.; Liu, W.; Wills, D.N.; Crews, F.T. Periadolescent ethanol vapor exposure persistently reduces measures of hippocampal neurogenesis that are associated with behavioral outcomes in adulthood. Neuroscience 2013, 244, 1-15.

31. Vetreno, R.P.; Yaxley, R.; Paniagua, B.; Crews, F.T. Diffusion tensor imaging reveals adolescent binge ethanol-induced brain structural integrity alterations in adult rats that correlate with behavioral dysfunction. Addict. Biol. 2016, 21, 939-953.

32. Rylkova, D.; Shah, H.P.; Small, E.; Bruijnzeel, A.W. Deficit in brain reward function and acute and protracted anxiety-like behavior after discontinuation of a chronic alcohol liquid diet in rats. Psychopharmacology (Berlin) 2009, 203, 629-640.

33. Mcclintick, M.N.; Grant, K.A. Aggressive temperament predicts ethanol self-administration in late adolescent male and female rhesus macaques. Psychopharmacology (Berlin) 2016, 233, 3965-3976.

34. Egli, M.; Koob, G.F.; Edwards, S. Alcohol dependence as a chronic pain disorder. Neurosci. Biobehav. Rev. 2012, 36, 2179-2192.

35. Buck, C.L.; Malavar, J.C.; George, O.; Koob, G.F.; Vendruscolo, L.F. Anticipatory 50 kHz ultrasonic vocalizations are associated with escalated alcohol intake in dependent rats. Behav. Brain. Res. 2014, $271,171-176$.

36. Somkuwar, S.S.; Vendruscolo, L.F.; Fannon, M.J.; Schmeichel, B.E.; Nguyen, T.B.; Guevara, J.; Sidhu, H.; Contet, C.; Zorrilla, E.P.; Mandyam, C.D. Abstinence from prolonged ethanol exposure affects plasma corticosterone, glucocorticoid receptor signaling and stress-related behaviors. Psychoneuroendocrinology 2017, 84, 17-31.

37. Jury, N.J.; Diberto, J.F.; Kash, T.L.; Holmes, A. Sex differences in the behavioral sequelae of chronic ethanol exposure. Alcohol 2017, 58, 53-60.

38. Sidhu, H.; Kreifeldt, M.; Contet, C. Affective disturbances during withdrawal from chronic intermittent ethanol inhalation in C57BL/6J and DBA/2J male mice. Alcohol. Clin. Exp. Res. 2018, 42, 1281-1290.

39. Holleran, K.M.; Winder, D.G. Preclinical voluntary drinking models for alcohol abstinence-induced affective disturbances in mice. Genes Brain Behav. 2017, 16, 8-14.

40. Lee, A.M.; Zou, M.E.; Lim, J.P.; Stecher, J.; Mcmahon, T.; Messing, R.O. Deletion of Prkcz increases intermittent ethanol consumption in mice. Alcohol. Clin. Exp. Res. 2014, 38, 170-178. 
41. Seif, T.; Simms, J.A.; Lei, K.; Wegner, S.; Bonci, A.; Messing, R.O.; Hopf, F.W. D-serine and d-cycloserine reduce compulsive alcohol intake in rats. Neuropsychopharmacology 2015, 40, 2357-2367.

42. Millan, E.Z.; Reese, R.M.; Grossman, C.D.; Chaudhri, N.; Janak, P.H. Nucleus accumbens and posterior amygdala mediate cue-triggered alcohol seeking and suppress behavior during the omission of alcohol-predictive cues. Neuropsychopharmacology 2015, 40, 2555-2565.

43. Hopf, F.W.; Chang, S.J.; Sparta, D.R.; Bowers, M.S.; Bonci, A. Motivation for alcohol becomes resistant to quinine adulteration after 3 to 4 months of intermittent alcohol self-administration. Alcohol. Clin. Exp. Res. 2010, 34, 1565-1573.

44. Carnicella, S.; Ron, D.; Barak, S. Intermittent ethanol access schedule in rats as a preclinical model of alcohol abuse. Alcohol 2014, 48, 243-252.

45. Lim, J.P.; Zou, M.E.; Janak, P.H.; Messing, R.O. Responses to ethanol in C57BL/6 versus C57BL/6 x 129 hybrid mice. Brain Behav. 2012, 2, 22-31.

46. Li, J.; Nie, H.; Bian, W.; Dave, V.; Janak, P.H.; Ye, J.H. Microinjection of glycine into the ventral tegmental area selectively decreases ethanol consumption. J. Pharmacol. Exp. Ther. 2012, 341, 196-204.

47. Carnicella, S.; Amamoto, R.; Ron, D. Excessive alcohol consumption is blocked by glial cell line-derived neurotrophic factor. Alcohol 2009, 43, 35-43.

48. Barak, S.; Carnicella, S.; Yowell, Q.V.; Ron, D. Glial cell line-derived neurotrophic factor reverses alcohol-induced allostasis of the mesolimbic dopaminergic system: Implications for alcohol reward and seeking. J. Neurosci. 2011, 31, 9885-9894.

49. Barak, S.; Ahmadiantehrani, S.; Kharazia, V.; Ron, D. Positive autoregulation of GDNF levels in the ventral tegmental area mediates long-lasting inhibition of excessive alcohol consumption. Transl. Psychiatry 2011, 1 , e60.

50. George, O.; Sanders, C.; Freiling, J.; Grigoryan, E.; Vu, S.; Allen, C.D.; Crawford, E.; Mandyam, C.D.; Koob, G.F. Recruitment of medial prefrontal cortex neurons during alcohol withdrawal predicts cognitive impairment and excessive alcohol drinking. Proc. Natl. Acad. Sci. USA 2012, 109, 18156-18161.

51. Wise, R.A. Voluntary ethanol intake in rats following exposure to ethanol on various schedules. Psychopharmacologia 1973, 29, 203-210.

52. Momeni, S.; Sharif, M.; Agren, G.; Roman, E. Individual differences in risk-related behaviors and voluntary alcohol intake in outbred Wistar rats. Behav. Pharmacol. 2014, 25, 206-215.

53. Simms, J.A.; Nielsen, C.K.; Li, R.; Bartlett, S.E. Intermittent access ethanol consumption dysregulates CRF function in the hypothalamus and is attenuated by the CRF-R1 antagonist, CP-376395. Addict. Biol. 2014, 19, 606-611.

54. Simms, J.A.; Steensland, P.; Medina, B.; Abernathy, K.E.; Chandler, L.J.; Wise, R.; Bartlett, S.E. Intermittent access to $20 \%$ ethanol induces high ethanol consumption in long-evans and wistar rats. Alcohol. Clin. Exp. Res. 2008, 32, 1816-1823.

55. Kimbrough, A.; Kim, S.; Cole, M.; Brennan, M.; George, O. Intermittent access to ethanol drinking facilitates the transition to excessive drinking after chronic intermittent ethanol vapor exposure. Alcohol. Clin. Exp. Res. 2017, 41, 1502-1509.

56. Nielsen, C.K.; Simms, J.A.; Pierson, H.B.; Li, R.; Saini, S.K.; Ananthan, S.; Bartlett, S.E. A novel delta opioid receptor antagonist, SoRI-9409, produces a selective and long-lasting decrease in ethanol consumption in heavy-drinking rats. Biol. Psychiatry 2008, 64, 974-981.

57. Simms, J.A.; Bito-Onon, J.J.; Chatterjee, S.; Bartlett, S.E. Long-Evans rats acquire operant self-administration of 20\% ethanol without sucrose fading. Neuropsychopharmacology 2010, 35, 1453-1463.

58. Feduccia, A.A.; Simms, J.A.; Mill, D.; Yi, H.Y.; Bartlett, S.E. Varenicline decreases ethanol intake and increases dopamine release via neuronal nicotinic acetylcholine receptors in the nucleus accumbens. Br. J. Pharmacol. 2014, 171, 3420-3431.

59. Melendez, R.I. Intermittent (every-other-day) drinking induces rapid escalation of ethanol intake and preference in adolescent and adult C57BL/6J mice. Alcohol. Clin. Exp. Res. 2011, 35, 652-658.

60. Hwa, L.S.; Chu, A.; Levinson, S.A.; Kayyali, T.M.; Debold, J.F.; Miczek, K.A. Persistent escalation of alcohol drinking in C57BL/6J mice with intermittent access to 20\% ethanol. Alcohol. Clin. Exp. Res. 2011, 35, 1938-1947.

61. Thiele, T.E.; Navarro, M. "Drinking in the dark" (DID) procedures: A model of binge-like ethanol drinking in non-dependent mice. Alcohol 2014, 48, 235-341. 
62. Sprow, G.M.; Thiele, T.E. The neurobiology of binge-like ethanol drinking: Evidence from rodent models. Physiol. Behav. 2012, 106, 325-331.

63. Lee, K.M.; Coehlo, M.A.; Solton, N.R.; Szumlinski, K.K. Negative affect and excessive alcohol intake incubate during protracted withdrawal from binge-drinking in adolescent, but not adult, mice. Front. Psychol. 2017, 8,1128

64. Belmer, A.; Patkar, O.L.; Lanoue, V.; Bartlett, S.E. 5-HT1A receptor-dependent modulation of emotional and neurogenic deficits elicited by prolonged consumption of alcohol. Sci. Rep. 2018, 8, 2099.

65. Rhodes, J.S.; Best, K.; Belknap, J.K.; Finn, D.A.; Crabbe, J.C. Evaluation of a simple model of ethanol drinking to intoxication in C57BL/6 mice. Physiol. Behav. 2005, 84, 53-63.

66. Rhodes, J.S.; Ford, M.M.; Yu, C.H.; Brown, L.L.; Finn, D.A.; Garland, T., Jr.; Crabbe, J.C. Mouse inbred strain differences in ethanol drinking to intoxication. Genes Brain Behav. 2007, 6, 1-18.

67. Bloodgood, D.W.; Hardaway, J.A.; Stanhope, C.M.; Pati, D.; Pina, M.M.; Neira, S.; Desai, S.; Boyt, K.M.; Palmiter, R.D.; Kash, T.L. Kappa opioid receptor and dynorphin signaling in the central amygdala regulates alcohol intake. Mol. Psychiatry 2018, 1, 1-13.

68. Pozhidayeva, D.Y.; Farris, S.P.; Goeke, C.M.; Firsick, E.J.; Townsley, K.G.; Guizzetti, M.; Ozburn, A.R. Chronic chemogenetic stimulation of the nucleus accumbens produces lasting reductions in binge drinking and ameliorates alcohol-related morphological and transcriptional changes. Brain Sci. 2020, 10, 109.

69. Evans, O.; Rodriguez-Borillo, O.; Font, L.; Currie, P.J.; Pastor, R. Alcohol binge drinking and anxiety-like behavior in socialized versus isolated C57BL/6J mice. Alcohol. Clin. Exp. Res. 2020, 44, 244-254.

70. Younis, R.M.; Wolstenholme, J.T.; Bagdas, D.; Bettinger, J.C.; Miles, M.F.; Damaj, M.I. Adolescent but not adult ethanol binge drinking modulates ethanol behavioral effects in mice later in life. Pharmacol. Biochem. Behav. 2019, 184, 172740.

71. Zhou, Y.; Leri, F.; Low, M.J.; Kreek, M.J. Sex differences in the effect of bupropion and naltrexone combination on alcohol drinking in mice. Pharmacol. Biochem. Behav. 2019, 181, 28-36.

72. Crowley, N.A.; Magee, S.N.; Feng, M.; Jefferson, S.J.; Morris, C.J.; Dao, N.C.; Brockway, D.F.; Luscher, B. Ketamine normalizes binge drinking-induced defects in glutamatergic synaptic transmission and ethanol drinking behavior in female but not male mice. Neuropharmacology 2019, 149, 35-44.

73. Vendruscolo, L.F.; Roberts, A.J. Operant alcohol self-administration in dependent rats: Focus on the vapor model. Alcohol 2014, 48, 277-286.

74. Tunstall, B.J.; Vendruscolo, L.F.; Allen-Worthington, K. Rat models of alcohol use disorder. In The Laboratory Rat; Wilson, R.P., Hankenson, F.C., Foley, P.L., Eds.; Academic Press: Suckow, Germany, 2020.

75. Ciccocioppo, R.; Economidou, D.; Cippitelli, A.; Cucculelli, M.; Ubaldi, M.; Soverchia, L.; Lourdusamy, A.; Massi, M. Genetically selected Marchigian Sardinian alcohol-preferring (msP) rats: An animal model to study the neurobiology of alcoholism. Addict. Biol. 2006, 11, 339-355.

76. Ciccocioppo, R. Genetically selected alcohol preferring rats to model human alcoholism. Curr. Top. Behav. Neurosci. 2013, 13, 251-269.

77. Li, T.K.; Lumeng, L.; Doolittle, D.P. Selective breeding for alcohol preference and associated responses. Behav. Genet. 1993, 23, 163-170.

78. Bell, R.L.; Rodd, Z.A.; Lumeng, L.; Murphy, J.M.; Mcbride, W.J. The alcohol-preferring P rat and animal models of excessive alcohol drinking. Addict. Biol. 2006, 11, 270-288.

79. Mcbride, W.J.; Rodd, Z.A.; Bell, R.L.; Lumeng, L.; Li, T.K. The alcohol-preferring (P) and high-alcohol-drinking (HAD) rats-animal models of alcoholism. Alcohol 2014, 48, 209-215.

80. Barkley-Levenson, A.M.; Crabbe, J.C. High drinking in the dark mice: A genetic model of drinking to intoxication. Alcohol 2014, 48, 217-223.

81. Crabbe, J.C.; Metten, P.; Rhodes, J.S.; Yu, C.H.; Brown, L.L.; Phillips, T.J.; Finn, D.A. A line of mice selected for high blood ethanol concentrations shows drinking in the dark to intoxication. Biol. Psychiatry 2009, $65,662-670$.

82. Crabbe, J.C.; Metten, P.; Belknap, J.K.; Spence, S.E.; Cameron, A.J.; Schlumbohm, J.P.; Huang, L.C.; Barkley-Levenson, A.M.; Ford, M.M.; Phillips, T.J. Progress in a replicated selection for elevated blood ethanol concentrations in HDID mice. Genes Brain Behav. 2014, 13, 236-246.

83. Grahame, N.J.; Li, T.K.; Lumeng, L. Selective breeding for high and low alcohol preference in mice. Behav. Genet. 1999, 29, 47-57. 
84. Chester, J.A.; Lumeng, L.; Li, T.K.; Grahame, N.J. High- and low-alcohol-preferring mice show differences in conditioned taste aversion to alcohol. Alcohol. Clin. Exp. Res. 2003, 27, 12-18.

85. Weera, M.M.; Agim, Z.S.; Cannon, J.R.; Chester, J.A. Genetic correlations between nicotine reinforcement-related behaviors and propensity toward high or low alcohol preference in two replicate mouse lines. Genes Brain Behav. 2019, 18, e12515.

86. Kissler, J.L.; Sirohi, S.; Reis, D.J.; Jansen, H.T.; Quock, R.M.; Smith, D.G.; Walker, B.M. The one-two punch of alcoholism: Role of central amygdala dynorphins/kappa-opioid receptors. Biol. Psychiatry 2014, 75, 774-782.

87. Gilpin, N.W.; Richardson, H.N.; Lumeng, L.; Koob, G.F. Dependence-induced alcohol drinking by alcohol-preferring (P) rats and outbred Wistar rats. Alcohol. Clin. Exp. Res. 2008, 32, 1688-1696.

88. Gilpin, N.W.; Richardson, H.N.; Koob, G.F. Effects of CRF1-receptor and opioid-receptor antagonists on dependence-induced increases in alcohol drinking by alcohol-preferring (P) rats. Alcohol. Clin. Exp. Res. 2008, 32, 1535-1542.

89. Staples, M.C.; Kim, A.; Mandyam, C.D. Dendritic remodeling of hippocampal neurons is associated with altered NMDA receptor expression in alcohol dependent rats. Mol. Cell Neurosci. 2015, 65, 153-162.

90. Leao, R.M.; Cruz, F.C.; Vendruscolo, L.F.; De Guglielmo, G.; Logrip, M.L.; Planeta, C.S.; Hope, B.T.; Koob, G.F.; George, $\mathrm{O}$. Chronic nicotine activates stress/reward-related brain regions and facilitates the transition to compulsive alcohol drinking. J. Neurosci. 2015, 35, 6241-6253.

91. De Guglielmo, G.; Crawford, E.; Kim, S.; Vendruscolo, L.F.; Hope, B.T.; Brennan, M.; Cole, M.; Koob, G.F.; George, O. Recruitment of a Neuronal Ensemble in the Central Nucleus of the Amygdala Is Required for Alcohol Dependence. J. Neurosci. 2016, 36, 9446-9453.

92. Contet, C.; Gardon, O.; Filliol, D.; Becker, J.A.; Koob, G.F.; Kieffer, B.L. Identification of genes regulated in the mouse extended amygdala by excessive ethanol drinking associated with dependence. Addict. Biol. 2011, 16, 615-619.

93. Kreifeldt, M.; Le, D.; Treistman, S.N.; Koob, G.F.; Contet, C. BK channel beta1 and beta4 auxiliary subunits exert opposite influences on escalated ethanol drinking in dependent mice. Front. Integr. Neurosci. 2013, $7,105$.

94. Becker, H.C.; Lopez, M.F. Increased ethanol drinking after repeated chronic ethanol exposure and withdrawal experience in C57BL/6 mice. Alcohol. Clin. Exp. Res. 2004, 28, 1829-1838.

95. Gorini, G.; Roberts, A.J.; Mayfield, R.D. Neurobiological signatures of alcohol dependence revealed by protein profiling. PLoS ONE 2013, 8, e82656.

96. Bajo, M.; Varodayan, F.P.; Madamba, S.G.; Robert, A.J.; Casal, L.M.; Oleata, C.S.; Siggins, G.R.; Roberto, M. IL-1 interacts with ethanol effects on GABAergic transmission in the mouse central amygdala. Front. Pharmacol. 2015, 6, 49.

97. Kreifeldt, M.; Cates-Gatto, C.; Roberts, A.J.; Contet, C. BK Channel beta1 subunit contributes to behavioral adaptations elicited by chronic intermittent ethanol exposure. Alcohol. Clin. Exp. Res. 2015, 39, 2394-2402.

98. Schweitzer, P.; Cates-Gatto, C.; Varodayan, F.P.; Nadav, T.; Roberto, M.; Lasek, A.W.; Roberts, A.J. Dependence-induced ethanol drinking and GABA neurotransmission are altered in Alk deficient mice. Neuropharmacology 2016, 107, 1-8.

99. Kimbrough, A.; Lurie, D.J.; Collazo, A.; Kreifeldt, M.; Sidhu, H.; Macedo, G.C.; D'esposito, M.; Contet, C.; George, O. Brain-wide functional architecture remodeling by alcohol dependence and abstinence. Proc. Natl. Acad. Sci. USA 2020, 117, 2149-2159.

100. Rogers, J.; Wiener, S.G.; Bloom, F.E. Long-term ethanol administration methods for rats: Advantages of inhalation over intubation or liquid diets. Behav. Neural Biol. 1979, 27, 466-486.

101. Roberts, A.J.; Cole, M.; Koob, G.F. Intra-amygdala muscimol decreases operant ethanol self-administration in dependent rats. Alcohol. Clin. Exp. Res. 1996, 20, 1289-1298.

102. Roberts, A.J.; Heyser, C.J.; Cole, M.; Griffin, P.; Koob, G.F. Excessive ethanol drinking following a history of dependence: Animal model of allostasis. Neuropsychopharmacology 2000, 22, 581-594.

103. O'dell, L.E.; Roberts, A.J.; Smith, R.T.; Koob, G.F. Enhanced alcohol self-administration after intermittent versus continuous alcohol vapor exposure. Alcohol. Clin. Exp. Res. 2004, 28, 1676-1682.

104. Schulteis, G.; Markou, A.; Cole, M.; Koob, G.F. Decreased brain reward produced by ethanol withdrawal. Proc. Natl. Acad. Sci. USA 1995, 92, 5880-5884. 
105. Kononoff, J.; Kallupi, M.; Kimbrough, A.; Conlisk, D.; De Guglielmo, G.; George, O. Systemic and intra-habenular activation of the orphan g protein-coupled receptor gpr139 decreases compulsive-like alcohol drinking and hyperalgesia in alcohol-dependent rats. eNeuro 2018, 5, 742.

106. Noori, H.R.; Spanagel, R.; Hansson, A.C. Neurocircuitry for modeling drug effects. Addict. Biol. 2012, 17, 827-864.

107. Metzger, D.; Clifford, J.; Chiba, H.; Chambon, P. Conditional site-specific recombination in mammalian cells using a ligand-dependent chimeric Cre recombinase. Proc. Natl. Acad. Sci. USA 1995, 92, 6991-6995.

108. Feil, R.; Brocard, J.; Mascrez, B.; Lemeur, M.; Metzger, D.; Chambon, P. Ligand-activated site-specific recombination in mice. Proc. Natl. Acad. Sci. USA 1996, 93, 10887-10890.

109. Broard, J.; Warot, X.; Wendling, O.; Messaddeq, N.; Vonesch, J.L.; Chambon, P.; Metzger, D. Spatio-temporally controlled site-specific somatic mutagenesis in the mouse. Proc. Natl. Acad. Sci. USA 1997, 94, 14559-14563.

110. Branda, C.S.; Dymecki, S.M. Talking about a revolution: The impact of site-specific recombinases on genetic analyses in mice. Dev. Cell 2004, 6, 7-28.

111. Boyden, E.S.; Zhang, F.; Bamberg, E.; Nagel, G.; Deisseroth, K. Millisecond-timescale, genetically targeted optical control of neural activity. Nat. Neurosci. 2005, 8, 1263-1268.

112. Chow, B.Y.; Han, X.; Dobry, A.S.; Qian, X.; Chuong, A.S.; Li, M.; Henninger, M.A.; Belfort, G.M.; Lin, Y.; Monahan, P.E.; et al. High-performance genetically targetable optical neural silencing by light-driven proton pumps. Nature 2010, 463, 98-102.

113. Zhang, F.; Wang, L.P.; Boyden, E.S.; Deisseroth, K. Channelrhodopsin-2 and optical control of excitable cells. Nat. Methods 2006, 3, 785-792.

114. Witten, I.B.; Steinberg, E.E.; Lee, S.Y.; Davidson, T.J.; Zalocusky, K.A.; Brodsky, M.; Yizhar, O.; Cho, S.L.; Gong, S.; Ramakrishnan, C.; et al. Recombinase-driver rat lines: Tools, techniques, and optogenetic application to dopamine-mediated reinforcement. Neuron 2011, 72, 721-733.

115. Kim, S.Y.; Adhikari, A.; Lee, S.Y.; Marshel, J.H.; Kim, C.K.; Mallory, C.S.; Lo, M.; Pak, S.; Mattis, J.; Lim, B.K.; et al. Diverging neural pathways assemble a behavioural state from separable features in anxiety. Nature 2013, 496, 219-223.

116. De Guglielmo, G.; Kallupi, M.; Pomrenze, M.B.; Crawford, E.; Simpson, S.; Schweitzer, P.; Koob, G.F.; Messing, R.O.; George, O. Inactivation of a CRF-dependent amygdalofugal pathway reverses Addiction-like behaviors in alcohol-dependent rats. Nat. Commun. 2019, 10, 1238.

117. Torruella-Suarez, M.L.; Vandenberg, J.R.; Cogan, E.S.; Tipton, G.J.; Teklezghi, A.; Dange, K.; Patel, G.K.; Mchenry, J.A.; Hardaway, J.A.; Kantak, P.A.; et al. Manipulations of central amygdala neurotensin neurons alter the consumption of ethanol and sweet fluids in mice. J. Neurosci. 2020, 40, 632-647.

118. Avegno, E.M.; Lobell, T.D.; Itoga, C.A.; Baynes, B.B.; Whitaker, A.M.; Weera, M.M.; Edwards, S.; Middleton, J.W.; Gilpin, N.W. Central amygdala circuits mediate hyperalgesia in alcohol-dependent rats. J. Neurosci. 2018, 38, 7761-7773.

119. Juarez, B.; Morel, C.; Ku, S.M.; Liu, Y.; Zhang, H.; Montgomery, S.; Gregoire, H.; Ribeiro, E.; Crumiller, M.; Roman-Ortiz, C.; et al. Midbrain circuit regulation of individual alcohol drinking behaviors in mice. Nat. Commun. 2017, 8, 2220.

120. Budygin, E.A.; Bass, C.E.; Grinevich, V.P.; Deal, A.L.; Bonin, K.D.; Weiner, J.L. Opposite consequences of tonic and phasic increases in accumbal dopamine on alcohol-seeking behavior. iScience 2020, 23, 100877.

121. Bass, C.E.; Grinevich, V.P.; Gioia, D.; Day-Brown, J.D.; Bonin, K.D.; Stuber, G.D.; Weiner, J.L.; Budygin, E.A. Optogenetic stimulation of VTA dopamine neurons reveals that tonic but not phasic patterns of dopamine transmission reduce ethanol self-administration. Front. Behav. Neurosci. 2013, 7, 173.

122. Mcginnis, M.M.; Parrish, B.C.; Mccool, B.A. Withdrawal from chronic ethanol exposure increases postsynaptic glutamate function of insular cortex projections to the rat basolateral amygdala. Neuropharmacology 2020, $172,108129$.

123. Seif, T.; Chang, S.J.; Simms, J.A.; Gibb, S.L.; Dadgar, J.; Chen, B.T.; Harvey, B.K.; Ron, D.; Messing, R.O.; Bonci, A.; et al. Cortical activation of accumbens hyperpolarization-active NMDARs mediates aversion-resistant alcohol intake. Nat. Neurosci. 2013, 16, 1094-1100.

124. Roth, B.L. DREADDs for neuroscientists. Neuron 2016, 89, 683-694.

125. Alexander, G.M.; Rogan, S.C.; Abbas, A.I.; Armbruster, B.N.; Pei, Y.; Allen, J.A.; Nonneman, R.J.; Hartmann, J.; Moy, S.S.; Nicolelis, M.A.; et al. Remote control of neuronal activity in transgenic mice expressing evolved G protein-coupled receptors. Neuron 2009, 63, 27-39. 
126. Zhu, H.; Aryal, D.K.; Olsen, R.H.; Urban, D.J.; Swearingen, A.; Forbes, S.; Roth, B.L.; Hochgeschwender, U. Cre-dependent DREADD (Designer Receptors Exclusively Activated by Designer Drugs) mice. Genesis 2016, 54, 439-446.

127. Zhu, H.; Pleil, K.E.; Urban, D.J.; Moy, S.S.; Kash, T.L.; Roth, B.L. Chemogenetic inactivation of ventral hippocampal glutamatergic neurons disrupts consolidation of contextual fear memory. Neuropsychopharmacology 2014, 39, 1880-1892.

128. Nakajima, K.; Wess, J. Design and functional characterization of a novel, arrestin-biased designer G protein-coupled receptor. Mol. Pharmacol. 2012, 82, 575-582.

129. Vetere, G.; Kenney, J.W.; Tran, L.M.; Xia, F.; Steadman, P.E.; Parkinson, J.; Josselyn, S.A.; Frankland, P.W. Chemogenetic interrogation of a brain-wide fear memory network in mice. Neuron 2017, 94, 363-374.

130. Cassataro, D.; Bergfeldt, D.; Malekian, C.; Van Snellenberg, J.X.; Thanos, P.K.; Fishell, G.; Sjulson, L. Reverse pharmacogenetic modulation of the nucleus accumbens reduces ethanol consumption in a limited access paradigm. Neuropsychopharmacology 2014, 39, 283-290.

131. Anderson, R.I.; Lopez, M.F.; Griffin, W.C.; Haun, H.L.; Bloodgood, D.W.; Pati, D.; Boyt, K.M.; Kash, T.L.; Becker, H.C. Dynorphin-kappa opioid receptor activity in the central amygdala modulates binge-like alcohol drinking in mice. Neuropsychopharmacology 2019, 44, 1084-1092.

132. McGinnis, M.M.; Parrish, B.C.; Chappell, A.M.; Alexander, N.J.; Mccool, B.A. Chronic ethanol differentially modulates glutamate release from dorsal and ventral prefrontal cortical inputs onto rat basolateral amygdala principal neurons. eNeuro 2020, 7.

133. Jendryka, M.; Palchaudhuri, M.; Ursu, D.; Van Der Veen, B.; Liss, B.; Katzel, D.; Nissen, W.; Pekcec, A. Pharmacokinetic and pharmacodynamic actions of clozapine-N-oxide, clozapine, and compound 21 in DREADD-based chemogenetics in mice. Sci. Rep. 2019, 9, 4522.

134. Martinez, V.K.; Saldana-Morales, F.; Sun, J.J.; Zhu, P.J.; Costa-Mattioli, M.; Ray, R.S. Off-target effects of clozapine-n-oxide on the chemosensory reflex are masked by high stress levels. Front. Physiol. 2019, 10, 521.

135. Ilg, A.K.; Enkel, T.; Bartsch, D.; Bahner, F. Behavioral effects of acute systemic low-dose clozapine in wild-type rats: Implications for the use of dreadds in behavioral neuroscience. Front. Behav. Neurosci. 2018, 12, 173.

136. MacLaren, D.A.; Browne, R.W.; Shaw, J.K.; Krishnan Radhakrishnan, S.; Khare, P.; Espana, R.A.; Clark, S.D. Clozapine N-Oxide administration produces behavioral effects in long-evans rats: Implications for designing DREADD Experiments. eNeuro 2016, 3, 934-936.

137. Tsien, R.Y. Fluorescence measurement and photochemical manipulation of cytosolic free calcium. Trends Neurosci. 1988, 11, 419-424.

138. Mao, B.Q.; Hamzei-Sichani, F.; Aronov, D.; Froemke, R.C.; Yuste, R. Dynamics of spontaneous activity in neocortical slices. Neuron 2001, 32, 883-898.

139. Stosiek, C.; Garaschuk, O.; Holthoff, K.; Konnerth, A. In vivo two-photon calcium imaging of neuronal networks. Proc. Natl. Acad. Sci. USA 2003, 100, 7319-7324.

140. Siciliano, C.A.; Noamany, H.; Chang, C.J.; Brown, A.R.; Chen, X.; Leible, D.; Lee, J.J.; Wang, J.; Vernon, A.N.; Vander WeelE, C.M.; et al. A cortical-brainstem circuit predicts and governs compulsive alcohol drinking. Science 2019, 366, 1008-1012.

141. Johnston, D.L.; Liu, P.; Wismer, G.L.; Rosen, B.R.; Stark, D.D.; New, P.F.; Okada, R.D.; Brady, T.J. Magnetic resonance imaging: Present and future applications. Can. Med. Assoc. J. 1985, 132, 765-777.

142. Denic, A.; Macura, S.I.; Mishra, P.; Gamez, J.D.; Rodriguez, M.; Pirko, I. MRI in rodent models of brain disorders. Neurotherapeutics 2011, 8, 3-18.

143. Glover, G.H. Overview of functional magnetic resonance imaging. Neurosurg. Clin. N. Am. 2011, 22, $133-139$.

144. Erturk, A.; Mauch, C.P.; Hellal, F.; Forstner, F.; Keck, T.; Becker, K.; Jahrling, N.; Steffens, H.; Richter, M.; Hubener, M.; et al. Three-dimensional imaging of the unsectioned adult spinal cord to assess axon regeneration and glial responses after injury. Nat. Med. 2011, 18, 166-171.

145. Renier, N.; Wu, Z.; Simon, D.J.; Yang, J.; Ariel, P.; Tessier-Lavigne, M. iDISCO: A simple, rapid method to immunolabel large tissue samples for volume imaging. Cell 2014, 159, 896-910.

146. Renier, N.; Adams, E.L.; Kirst, C.; Wu, Z.; Azevedo, R.; Kohl, J.; Autry, A.E.; Kadiri, L.; Umadevi Venkataraju, K.; Zhou, Y.; et al. Mapping of brain activity by automated volume analysis of immediate early genes. Cell 2016, 165, 1789-1802. 
147. Pan, C.; Cai, R.; Quacquarelli, F.P.; Ghasemigharagoz, A.; Lourbopoulos, A.; Matryba, P.; Plesnila, N.; Dichgans, M.; Hellal, F.; Erturk, A. Shrinkage-mediated imaging of entire organs and organisms using uDISCO. Nat. Methods 2016, 13, 859-867.

148. Chung, K.; Wallace, J.; Kim, S.Y.; Kalyanasundaram, S.; Andalman, A.S.; Davidson, T.J.; Mirzabekov, J.J.; Zalocusky, K.A.; Mattis, J.; Denisin, A.K.; et al. Structural and molecular interrogation of intact biological systems. Nature 2013, 497, 332-337.

149. Erturk, A.; Becker, K.; Jahrling, N.; Mauch, C.P.; Hojer, C.D.; Egen, J.G.; Hellal, F.; Bradke, F.; Sheng, M.; Dodt, H.U. Three-dimensional imaging of solvent-cleared organs using 3DISCO. Nat. Protoc. 2012, 7, 1983-1995.

150. Liebmann, T.; Renier, N.; Bettayeb, K.; Greengard, P.; Tessier-Lavigne, M.; Flajolet, M. Three-Dimensional Study of Alzheimer's Disease Hallmarks Using the iDISCO Clearing Method. Cell Rep. 2016, 16, 1138-1152.

151. Bullmore, E.; Sporns, O. Complex brain networks: Graph theoretical analysis of structural and functional systems. Nat. Rev. Neurosci. 2009, 10, 186-198.

152. Gong, G.; He, Y.; Concha, L.; Lebel, C.; Gross, D.W.; Evans, A.C.; Beaulieu, C. Mapping anatomical connectivity patterns of human cerebral cortex using in vivo diffusion tensor imaging tractography. Cereb. Cortex 2009, 19, 524-536.

153. Hagmann, P.; Cammoun, L.; Gigandet, X.; Meuli, R.; Honey, C.J.; Wedeen, V.J.; Sporns, O. Mapping the structural core of human cerebral cortex. PLoS Biol. 2008, 6, e159.

154. Bassett, D.S.; Bullmore, E.; Verchinski, B.A.; Mattay, V.S.; Weinberger, D.R.; Meyer-Lindenberg, A. Hierarchical organization of human cortical networks in health and schizophrenia. J. Neurosci. 2008, 28, 9239-9248.

155. He, Y.; Chen, Z.J.; Evans, A.C. Small-world anatomical networks in the human brain revealed by cortical thickness from MRI. Cereb. Cortex 2007, 17, 2407-2419.

156. Eguiluz, V.M.; Chialvo, D.R.; Cecchi, G.A.; Baliki, M.; Apkarian, A.V. Scale-free brain functional networks. Phys. Rev. Lett. 2005, 94, 018102.

157. Achard, S.; Salvador, R.; Whitcher, B.; Suckling, J.; Bullmore, E. A resilient, low-frequency, small-world human brain functional network with highly connected association cortical hubs. J. Neurosci. 2006, 26, 63-72.

158. Achard, S.; Bullmore, E. Efficiency and cost of economical brain functional networks. PLoS Comput. Biol. 2017, 3, e17.

159. Liu, Y.; Liang, M.; Zhou, Y.; He, Y.; Hao, Y.; Song, M.; Yu, C.; Liu, H.; Liu, Z.; Jiang, T. Disrupted small-world networks in schizophrenia. Brain 2008, 131, 945-961.

160. Salvador, R.; Suckling, J.; Coleman, M.R.; Pickard, J.D.; Menon, D.; Bullmore, E. Neurophysiological architecture of functional magnetic resonance images of human brain. Cereb. Cortex 2005, 15, 1332-1342.

161. Van Den Heuvel, M.P.; Stam, C.J.; Boersma, M.; Hulshoff Pol, H.E. Small-world and scale-free organization of voxel-based resting-state functional connectivity in the human brain. Neuroimage 2008, 43, 528-539.

162. Micheloyannis, S.; Pachou, E.; Stam, C.J.; Breakspear, M.; Bitsios, P.; Vourkas, M.; Erimaki, S.; Zervakis, M. Small-world networks and disturbed functional connectivity in schizophrenia. Schizophr. Res. 2006, 87, 60-66.

163. Stam, C.J.; Jones, B.F.; Nolte, G.; Breakspear, M.; Scheltens, P. Small-world networks and functional connectivity in Alzheimer's disease. Cereb. Cortex 2004, 17, 92-99.

164. Bassett, D.S.; Bullmore, E. Small-world brain networks. Neuroscientist 2006, 12, 512-523.

165. Deuker, L.; Bullmore, E.T.; Smith, M.; Christensen, S.; Nathan, P.J.; Rockstroh, B.; Bassett, D.S. Reproducibility of graph metrics of human brain functional networks. Neuroimage 2009, 47, 1460-1468.

166. Stam, C.J. Functional connectivity patterns of human magnetoencephalographic recordings: A 'small-world' network? Neurosci. Lett. 2004, 355, 25-28.

167. Bassett, D.S.; Meyer-Lindenberg, A.; Achard, S.; Duke, T.; Bullmore, E. Adaptive reconfiguration of fractal small-world human brain functional networks. Proc. Natl. Acad. Sci. USA 2006, 103, 19518-19523.

168. Jeong, H.; Mason, S.P.; Barabasi, A.L.; Oltvai, Z.N. Lethality and centrality in protein networks. Nature 2001, $411,41-42$.

169. Barabasi, A.L. Scale-free networks: A decade and beyond. Science 2009, 325, 412-413.

170. Babu, M.; Vlasblom, J.; Pu, S.; Guo, X.; Graham, C.; Bean, B.D.; Burston, H.E.; Vizeacoumar, F.J.; Snider, J.; Phanse, S.; et al. Interaction landscape of membrane-protein complexes in Saccharomyces cerevisiae. Nature 2012, 489, 585-589. 
171. Wheeler, A.L.; Teixeira, C.M.; Wang, A.H.; Xiong, X.; Kovacevic, N.; Lerch, J.P.; Mcintosh, A.R.; Parkinson, J.; Frankland, P.W. Identification of a functional connectome for long-term fear memory in mice. PLoS Comput. Biol. 2013, 9, e1002853.

172. Jarrell, T.A.; Wang, Y.; Bloniarz, A.E.; Brittin, C.A.; Xu, M.; Thomson, J.N.; Albertson, D.G.; Hall, D.H.; Emmons, S.W. The connectome of a decision-making neural network. Science 2012, 337, 437-444.

173. Oh, S.W.; Harris, J.A.; Ng, L.; Winslow, B.; Cain, N.; Mihalas, S.; Wang, Q.; Lau, C.; Kuan, L.; Henry, A.M.; et al. A mesoscale connectome of the mouse brain. Nature 2014, 508, 207-214.

174. Varshney, L.R.; Chen, B.L.; Paniagua, E.; Hall, D.H.; Chklovskii, D.B. Structural properties of the Caenorhabditis elegans neuronal network. PLoS Comput. Biol. 2011, 7, e1001066.

175. Markov, N.T.; Ercsey-Ravasz, M.M.; Ribeiro Gomes, A.R.; Lamy, C.; Magrou, L.; Vezoli, J.; Misery, P.; Falchier, A.; Quilodran, R.; Gariel, M.A.; et al. weighted and directed interareal connectivity matrix for macaque cerebral cortex. Cereb. Cortex 2014, 24, 17-36.

176. Chiang, A.S.; Lin, C.Y.; Chuang, C.C.; Chang, H.M.; Hsieh, C.H.; Yeh, C.W.; Shih, C.T.; Wu, J.J.; Wang, G.T.; Chen, Y.C.; et al. Three-dimensional reconstruction of brain-wide wiring networks in Drosophila at single-cell resolution. Curr. Biol. 2011, 21,1-11.

177. Bullmore, E.; Sporns, O. The economy of brain network organization. Nat. Rev. Neurosci. 2012, 13, $336-349$.

178. Bargmann, C.I.; Marder, E. From the connectome to brain function. Nat. Methods 2013, 10, 483-490.

179. Cohen, J.R.; D'esposito, M. The Segregation and integration of distinct brain networks and their relationship to cognition. J. Neurosci. 2016, 36, 12083-12094.

180. Sporns, O. Graph theory methods: Applications in brain networks. Dialogues Clin. Neurosci. 2018, $20,111-121$.

181. Sporns, O.; Betzel, R.F. Modular Brain Networks. Annu. Rev. Psychol. 2016, 67, 613-640.

182. Humphries, M.D.; Gurney, K. Network 'small-world-ness': A quantitative method for determining canonical network equivalence. PLOS ONE 2008, 3, e0002051.

183. Rubinov, M.; Knock, S.A.; Stam, C.J.; Micheloyannis, S.; Harris, A.W.; Williams, L.M.; Breakspear, M. Small-world properties of nonlinear brain activity in schizophrenia. Hum. Brain Mapp. 2009, 30, 403-416.

184. Whitfield-Gabrieli, S.; Thermenos, H.W.; Milanovic, S.; Tsuang, M.T.; Faraone, S.V.; Mccarley, R.W.; Shenton, M.E.; Green, A.I.; Nieto-Castanon, A.; Laviolette, P.; et al. Hyperactivity and hyperconnectivity of the default network in schizophrenia and in first-degree relatives of persons with schizophrenia. Proc. Natl. Acad. Sci. USA 2009, 106, 1279-1284.

185. Van Den Heuvel, M.P.; Stam, C.J.; Kahn, R.S.; Hulshoff Pol, H.E. Efficiency of functional brain networks and intellectual performance. J. Neurosci. 2009, 29, 7619-7624.

186. Bassett, D.S.; Bullmore, E.T.; Meyer-Lindenberg, A.; Apud, J.A.; Weinberger, D.R.; Coppola, R. Cognitive fitness of cost-efficient brain functional networks. Proc. Natl. Acad. Sci. USA 2009, 106, 11747-11752.

187. Li, Y.; Liu, Y.; Li, J.; Qin, W.; Li, K.; Yu, C.; Jiang, T. Brain anatomical network and intelligence. PLoS Comput. Biol. 2009, 5, e1000395.

188. Sporns, O.; Chialvo, D.R.; Kaiser, M.; Hilgetag, C.C. Organization, development and function of complex brain networks. Trends Cogn. Sci. 2004, 8, 418-425.

189. Wang, J.; Zuo, X.; He, Y. Graph-based network analysis of resting-state functional MRI. Front. Syst. Neurosci. 2010, 4, 16.

190. Sporns, O.; Honey, C.J.; Kotter, R. Identification and classification of hubs in brain networks. PLoS ONE 2007, 2, e1049.

191. Guimera, R.; Mossa, S.; Turtschi, A.; Amaral, L.A. The worldwide air transportation network: Anomalous centrality, community structure, and cities' global roles. Proc. Natl. Acad. Sci. USA 2005, 102, 7794-7799.

192. Guimera, R.; Nunes Amaral, L.A. Functional cartography of complex metabolic networks. Nature 2005, 433, 895-900.

193. Rubinov, M.; Sporns, O. Complex network measures of brain connectivity: Uses and interpretations. Neuroimage 2010, 52, 1059-1069.

194. Arnatkeviciute, A.; Fulcher, B.D.; Fornito, A. Uncovering the transcriptional correlates of hub connectivity in neural networks. Front. Neural Circuits 2019, 13, 47.

195. George, O.; Koob, G.F. Individual differences in prefrontal cortex function and the transition from drug use to drug dependence. Neurosci. Biobehav. Rev. 2010, 35, 232-247.

196. Vergara, V.M.; Liu, J.; Claus, E.D.; Hutchison, K.; Calhoun, V. Alterations of resting state functional network connectivity in the brain of nicotine and alcohol users. Neuroimage $\mathbf{2 0 1 7}, \mathbf{1 5 1}, \mathbf{4 5 - 5 4 .}$ 
197. Huang, W.; King, J.A.; Ursprung, W.W.; Zheng, S.; Zhang, N.; Kennedy, D.N.; Ziedonis, D.; Difranza, J.R. The development and expression of physical nicotine dependence corresponds to structural and functional alterations in the anterior cingulate-precuneus pathway. Brain Behav. 2014, 4, 408-417.

198. Cavanna, A.E.; Trimble, M.R. The precuneus: A review of its functional anatomy and behavioural correlates. Brain 2006, 129, 564-583.

199. Utevsky, A.V.; Smith, D.V.; Huettel, S.A. Precuneus is a functional core of the default-mode network. J. Neurosci. 2014, 34, 932-940.

200. Tomasi, D.; Volkow, N.D.; Wang, G.J.; Wang, R.; Telang, F.; Caparelli, E.C.; Wong, C.; Jayne, M.; Fowler, J.S. Methylphenidate enhances brain activation and deactivation responses to visual attention and working memory tasks in healthy controls. Neuroimage 2011, 54, 3101-3110.

201. Goldstein, R.Z.; Woicik, P.A.; Maloney, T.; Tomasi, D.; Alia-Klein, N.; Shan, J.; Honorio, J.; Samaras, D.; Wang, R.; Telang, F; et al. Oral methylphenidate normalizes cingulate activity in cocaine addiction during a salient cognitive task. Proc. Natl. Acad. Sci. USA 2010, 107, 16667-16672.

202. Konova, A.B.; Moeller, S.J.; Tomasi, D.; Volkow, N.D.; Goldstein, R.Z. Effects of methylphenidate on resting-state functional connectivity of the mesocorticolimbic dopamine pathways in cocaine addiction. JAMA Psychiatry 2013, 70, 857-868.

203. Ma, L.; Steinberg, J.L.; Moeller, F.G.; Johns, S.E.; Narayana, P.A. Effect of cocaine dependence on brain connections: Clinical implications. Exp. Rev. Neurother. 2015, 15, 1307-1319.

204. Konova, A.B.; Moeller, S.J.; Tomasi, D.; Goldstein, R.Z. Effects of chronic and acute stimulants on brain functional connectivity hubs. Brain Res. 2015, 1628, 147-156.

205. Xie, C.; Shao, Y.; Fu, L.; Goveas, J.; Ye, E.; Li, W.; Cohen, A.D.; Chen, G.; Zhang, Z.; Yang, Z. Identification of hyperactive intrinsic amygdala network connectivity associated with impulsivity in abstinent heroin addicts. Behav. Brain Res. 2011, 216, 639-646.

206. Liu, J.; Qin, W.; Yuan, K.; Li, J.; Wang, W.; Li, Q.; Wang, Y.; Sun, J.; Von Deneen, K.M.; Liu, Y.; et al. Interaction between dysfunctional connectivity at rest and heroin cues-induced brain responses in male abstinent heroin-dependent individuals. PLoS ONE 2011, 6, e23098.

207. Weiland, B.J.; Sabbineni, A.; Calhoun, V.D.; Welsh, R.C.; Bryan, A.D.; Jung, R.E.; Mayer, A.R.; Hutchison, K.E. Reduced left executive control network functional connectivity is associated with alcohol use disorders. Alcohol. Clin. Exp. Res. 2014, 38, 2445-2453.

208. Kim, S.; Im, S.; Lee, J.; Lee, S.G. Disrupted control network connectivity in abstinent patients with alcohol dependence. Psychiatry Investig. 2017, 14, 325-332.

209. Shokri-Kojori, E.; Tomasi, D.; Wiers, C.E.; Wang, G.J.; Volkow, N.D. Alcohol affects brain functional connectivity and its coupling with behavior: Greater effects in male heavy drinkers. Mol. Psychiatry 2017, 22, 1185-1195.

210. Huang, Y.; Mohan, A.; De Ridder, D.; Sunaert, S.; Vanneste, S. The neural correlates of the unified percept of alcohol-related craving: A fMRI and EEG study. Sci. Rep. 2018, 8, 923.

211. Sinha, R.; Li, C.S. Imaging stress- and cue-induced drug and alcohol craving: Association with relapse and clinical implications. Drug Alcohol Rev. 2007, 26, 25-31.

212. Arienzo, D.; Happer, J.P.; Molnar, S.M.; Alderson-Myers, A.; Marinkovic, K. Binge drinking is associated with altered resting state functional connectivity of reward-salience and top down control networks. Brain Imaging Behav. 2019, 10, 1-16.

213. Fede, S.J.; Abrahao, K.P.; Cortes, C.R.; Grodin, E.N.; Schwandt, M.L.; George, D.T.; Diazgranados, N.; Ramchandani, V.A.; Lovinger, D.M.; Momenan, R. Alcohol effects on globus pallidus connectivity: Role of impulsivity and binge drinking. PLoS ONE 2020, 15, e0224906.

214. Orsini, C.A.; Colon-Perez, L.M.; Heshmati, S.C.; Setlow, B.; Febo, M. Functional connectivity of chronic cocaine use reveals progressive neuroadaptations in neocortical, striatal, and limbic networks. eNeuro 2018, 5.

215. Perez-Ramirez, U.; Diaz-Parra, A.; Ciccocioppo, R.; Canals, S.; Moratal, D. Brain functional connectivity alterations in a rat model of excessive alcohol drinking: A resting-state network analysis. Conf. Proc. IEEE Eng. Med. Biol. Soc. 2017, 106, 3016-3019.

216. Cho, J.H.; Rendall, S.D.; Gray, J.M. Brain-wide maps of Fos expression during fear learning and recall. Learn. Mem. 2017, 24, 169-181. 
217. Kimbrough, A.; Smith, L.C.; Kallupi, M.; Simpson, S.; Collazo, A.; George, O. Characterization of the brain functional architecture of psychostimulant withdrawal using single-cell whole brain imaging. bioRxiv 2019, $1,743799$.

218. Gallen, C.L.; Baniqued, P.L.; Chapman, S.B.; Aslan, S.; Keebler, M.; Didehbani, N.; D'esposito, M. Modular brain network organization predicts response to cognitive training in older adults. PLoS ONE 2016, 11, e0169015.

219. Bertolero, M.A.; Thomas Yeo, B.T.; Bassett, D.S.; D'esposito, M. A mechanistic model of connector hubs, modularity and cognition. Nat. Hum. Behav. 2018, 2, 765-777.

220. De Haan, W.; Van Der Flier, W.M.; Koene, T.; Smits, L.L.; Scheltens, P.; Stam, C.J. Disrupted modular brain dynamics reflect cognitive dysfunction in Alzheimer's disease. Neuroimage 2012, 59, 3085-3093.

221. Brier, M.R.; Thomas, J.B.; Fagan, A.M.; Hassenstab, J.; Holtzman, D.M.; Benzinger, T.L.; Morris, J.C.; Ances, B.M. Functional connectivity and graph theory in preclinical Alzheimer's disease. Neurobiol. Aging 2014, 35, 757-768.

222. Arnemann, K.L.; Chen, A.J.; Novakovic-Agopian, T.; Gratton, C.; Nomura, E.M.; D'esposito, M. Functional brain network modularity predicts response to cognitive training after brain injury. Neurology 2015, 84, 1568-1574.

223. Allen, W.E.; Denardo, L.A.; Chen, M.Z.; Liu, C.D.; Loh, K.M.; Fenno, L.E.; Ramakrishnan, C.; Deisseroth, K.; Luo, L. Thirst-associated preoptic neurons encode an aversive motivational drive. Science 2017, 357, 1149-1155.

224. Guenthner, C.J.; Miyamichi, K.; Yang, H.H.; Heller, H.C.; Luo, L. Permanent genetic access to transiently active neurons via TRAP: Targeted recombination in active populations. Neuron 2013, 78, 773-784.

225. Sych, Y.; Chernysheva, M.; Sumanovski, L.T.; Helmchen, F. High-density multi-fiber photometry for studying large-scale brain circuit dynamics. Nat. Methods 2019, 16, 553-560.

226. Winslow, B.T.; Onysko, M.; Hebert, M. Medications for alcohol use disorder. Am. Fam. Phys. 2016, 93, 457-465.

227. Morris, L.S.; Baek, K.; Tait, R.; Elliott, R.; Ersche, K.D.; Flechais, R.; Mcgonigle, J.; Murphy, A.; Nestor, L.J.; Orban, C.; et al. Naltrexone ameliorates functional network abnormalities in alcohol-dependent individuals. Addict. Biol. 2018, 23, 425-436.

228. Elton, A.; Dove, S.; Spencer, C.N.; Robinson, D.L.; Boettiger, C.A. Naltrexone acutely enhances connectivity between the ventromedial prefrontal cortex and a left frontoparietal network. Alcohol. Clin. Exp. Res. 2019, 43, 965-978. 